\title{
MINISTÉRIO PÚBLICO, AUTONOMIA FUNCIONAL E DISCRICIONARIEDADE: ampla atuação em políticas públicas, baixa accountability
}

\author{
Vanessa Elias de Oliveira ${ }^{7}$ \\ Gabriela Lotta ${ }^{2}$ \\ 琹 Natália Pires de Vasconcelos ${ }^{3}$
}

\section{Palavras-Chave \\ Ministério Público / autonomia / discricionariedade / accountability}

\section{SUMÁRIO}

1. Introdução - 2. Ministério Público, discricionariedade e autonomia funcional de promotores e procuradores - 3. Discricionariedade da burocracia do Ministério Público - 4. Ampliação da atuação, manutenção da autonomia sem accountability - 5. Considerações finais - 6 . Referências

\section{Resumo}

A literatura nacional já avançou no reconhecimento dos atores do sistema de justiça como atores com poder de veto e de interferência no policy making (Taylor, 2008), por meio de suas decisões, sejam elas judiciais ou extrajudiciais. Os estudos sobre estes atores, contudo, concentra-se especialmente na atuação de juízes, sendo ainda escassos trabalhos voltados para outros membros do sistema de justiça. O presente trabalho visa

Doutora em Ciência Política pela Universidade de São Paulo. Pesquisadora do CNPq. Professora de Ciência Política do Bacharelado em Políticas Públicas e da Pós-Graduação em Políticas Públicas da Universidade Federal do ABC (UFABC)

2Doutora em Ciência Política pela Universidade de São Paulo. Pesquisadora do CNPq. Professora e Pesquisadora de Administração Pública e Governo da Fundação Getúlio Vargas (FGV).

3 Doutora em Direito pela Universidade de São Paulo. LLM pela Yale University. Professora do Instituto de Ensino e Pesquisa (Insper). lançar luz sobre a atuação de promotores do Ministério Público, cuja autonomia e discricionariedade é fator essencial na seleção e condução de casos concretos. Assumindo o pressuposto de que o principal poder discricionário de um promotor de justiça diz respeito à possibilidade de não investigar ou processar, isto é, não dar encaminhamento a alguns casos que lhe chegam ao conhecimento, este trabalho é um primeiro esforço de atender a lacuna teórica apontada. Para além do esforço teórico, apresenta uma pesquisa exploratória, baseada em metodologia qualitativa, por meio da análise de Recomendações do Conselho Nacional do Ministério Público (CNMP) que tratam sobre autonomia funcional. A análise documental nos permite agregar elementos ao argumento da "autonomia sem accountability" (Kerche, 2007; Kerche et al., 2019), observada desde o início do processo de construção institucional do órgão, que não apenas se manteve presente como vem sendo reforçada por atos e normas do CNMP. Por outro lado, não parece haver um movimento institucional no sentido de ampliar a accountability, fazendo com que a atuação de promotores e procuradores seja pouco transparente para além do que está descrito nos processos administrativos ou judiciais. A autonomia é ampla, o controle é baixo. 


\title{
PUBLIC PROSECUTOR'S OFFICE, FUNCTIONAL AUTONOMY AND DISCRETIONARITY: broad performance in public policies, low accountability
}

\author{
Vanessa Elias de Oliveira \\ Gabriela Lotta \\ Natália Pires de Vasconcelos
}

\section{Key-words}

Public Prosecutor's Office / autonomy / discretionarity / accountability

\begin{abstract}
National literature has already advanced in recognizing the actors in the justice system as actors with veto power and interference in policy making (Taylor, 2008), through their decisions, whether judicial or extrajudicial. The studies on these actors, however, focus especially on the performance of judges, and there are still few studies aimed at other members of the justice system. This work focus on the performance of prosecutors from the Public Prosecutor's Office, whose autonomy and discretionarity is an essential factor in the selection and management of concrete cases. If the main discretionary power ofa prosecutor concernsthe possibility of not investigating or prosecuting, that is, not referring some cases that come to his or
\end{abstract}

her knowledge, this work is a first effort to address the theoretical gap pointed out. In addition to the theoretical effort, it presents an exploratory research, based on qualitative methodology, through the analysis of the Public Prosecutor's Office National Council (Conselho Nacional do Ministério Público CNMP) Recommendations that deal with functional autonomy. Documentary analysis allows us to add elements to the "autonomy without accountability" argument (Kerche, 2007; Kerche et al., 2019), observed since the beginning of the institutional construction process of the agency, which has not only remained present but has been reinforced by CNMP acts and rules. On the other hand, there does not seem to be an institutional movement towards expanding accountability, making the performance of prosecutors less transparent than what is described in administrative or judicial proceedings. Broad autonomy, low control. 


\section{INTRODUÇÃO}

A crescente interação entre os poderes e a compreensão dos impactos da atuação do sistema de justiça sobre as políticas públicas vêm sendo objeto de muitos estudos na área da ciência política e das políticas públicas. Desde o consenso acerca da "expansão global do Poder Judiciário", apontada no já clássico trabalho de Tate e Vallinder (1995), reconhece-se e discute-se como a atuação do Judiciário e demais órgãos do sistema de justiça (dentre eles o Ministério Público) interfere no processo decisório, de formulação, de implementação e até de avaliação das políticas públicas.

Além de "atores com poder de veto", atores do sistema de justiça operam direta ou indiretamente no policy making por meio de suas decisões, sejam elas judiciais ou extrajudiciais (Taylor, 2008). Em regra, decisões judiciais são analisadas a partir de trabalhos sobre as instituições e os atores do sistema de justiça, bem como o processo de consolidação institucional dos seus órgãos. Os estudos sobre estes atores, contudo, concentram-se especialmente no desempenho e organização dos juízes, sendo ainda escassos trabalhos que se voltam a outros membros relevantes do sistema. Pouco se sabe, ainda, sobre a discricionariedade da burocracia pública destes órgãos e de como esta discricionariedade afeta sua atuação e, por consequência, a garantia de direitos e as políticas públicas; mas, antes disso, o próprio acesso à justiça.

Ao mesmo tempo, na literatura sobre burocracia tem crescido, nos últimos anos, análises que buscam compreender como a discricionariedade dos implementadores de políticas impacta o acesso a elas e pode levar à (re)produção de desigualdades. Des- de o clássico estudo de Lipsky (1980), passando por autores mais contemporâneos (Maynard-Moody \& Musheno, 2003, 2016; Dubois, 2010; Moller, 2016) avançou-se na compreensão de como a burocracia, no uso de sua discricionariedade, opera processos que classificam os cidadãos entre merecedores ou não das políticas, impactando diretamente no seu acesso a bens e serviços públicos. Esta literatura pode lançar luz sobre a atuação de promotores no Ministério Público, cuja autonomia e discricionariedade também é fator essencial na seleção e condução de casos concretos.

Assumindo o pressuposto de que o principal poder discricionário de um promotor de justiça diz respeito à possibilidade de não investigar ou processar, isto é, não dar encaminhamento a alguns casos que lhe chegam ao conhecimento, este trabalho é um primeiro esforço de atender a lacuna teórica apontada acima.

Para dar conta do objetivo proposto apresentamos uma discussão teórica sobre o tema, agregando elementos para os estudos sobre autonomia e discricionariedade do Ministério Público. Em seguida, por meio de uma análise exploratória, examinamos documentos do Ministério Público, em especial as Recomendações do Conselho Nacional do Ministério Público (CNMP) que tratam sobre autonomia. Observamos que o CNMP atua no sentido de reforçar a autonomia do MP sem que isso implique, no entanto, aumento da accountability.

O artigo se estrutura da seguinte maneira: em primeiro lugar, discutimos a autonomia funcional de promotores e procuradores; em seguida, apresentamos a questão da discricionariedade da burocracia do Ministério Público; por fim, analisamos os dados 
qualitativos mencionados. Concluímos o artigo com algumas considerações sobre a discussão empreendida e com o apontamento de questões para uma agenda de pesquisa sobre o tema da discricionariedade dos atores do Ministério Público.

\section{MINISTÉRIO PÚBLICO, DISCRICIONARIEDADE E AUTONOMIA FUNCIONAL DE PROMOTORES E PROCURADORES}

A autonomia do Ministério Público já é de amplo conhecimento público e foi bastante discutida pela ciência política brasileira. Arantes (2002) faz uma análise do processo de reconstrução institucional do MP que culminou nas novas atribuições do órgão na Constituição de 1988, garantindo-Ihe ampla autonomia, capacidade de interferência no jogo político e ausência de mecanismos de controle. Para o autor, não apenas as mudanças institucionais asseguraram ampla margem de atuação para promotores e procuradores (com um número extraordinário de possibilidades de atuação na área cível) como, ademais, algumas imprecisões legais Ihes garantiram ampla discricionariedade. É o caso, por exemplo, da (in)definição de "interesse público", “(...) o que permitiu a promotores e procuradores postularem criativamente sua intervenção no processo civil como necessária para a preservação dos interesses gerais da sociedade" (Arantes, 2002, p.38). Assim, a independência funcional permite aos membros do MP estabelecerem suas prioridades de atuação "em meio a um enorme leque de funções que a instituição acumulou nas últimas décadas" (Arantes, 2002, p.117).

Ademais, os fortes traços endógenos que marcaram esse processo de reconstrução institucional do MP resultaram naquilo que o autor denomina por voluntarismo político dos seus membros, conceito este que

“(...) está baseado numa avaliação crítica e pessimista da sociedade civil (tanto de suas carências quanto de sua incapacidade de mobilização) e também dos poderes de Estado (que se encontrariam divorciados da sociedade e incapazes de garantir os direitos fundamentais). Desse binômio emerge o terceiro elemento da matriz ideológica do voluntarismo político: cabe ao Ministério Público tutelar os direitos dessa sociedade civil fraca, dirigindo suas ações prioritariamente contra o Estado inoperante e as instituições políticas muitas vezes corrompidas por interesses particularistas" (Arantes, 2002, p.119).

O voluntarismo político dos membros do MP decorreria, assim, dos poderes institucionais de atuação que eles se asseguraram, embasados em um discurso que invoca a hipossuficiência da sociedade civil na promoção de seus próprios interesses e direitos, somado à inoperância das instituições políticas tradicionais. Embora haja uma discussão sobre o peso desse fator endógeno, conforme apresentado por Carvalho e Leitão (2010), o fato é que o Ministério Público criado em 1988 assegura a seus atores ampla gama de possibilidades de atuação, sendo este o primeiro elemento importante para nossa análise.

Vale destacar que a ideia de "voluntarismo político" proposta por Arantes se diferencia da análise de Bonelli (2002) sobre o Ministério Público paulista. A autora contrapõe o profissionalismo (ou o que denomina de "ideologia profissional") à "política", e quando trata desta última volta-se ao direito dos membros do MP de se candidatarem a pos- 
tos políticos. A Constituição de 1988 vedou aos novos membros uma atuação político- partidária, mas permitiu o afastamento da carreira àqueles que haviam ingressado no Ministério Público até 1988, em relação aos quais estava mantido, portanto, o direito de assumirem cargos políticos. A vitória daqueles que defendiam a "ideologia profissional" explicaria, para ela, o insulamento conquistado na nova Carta: "O insulamento da carreira frente às pressões externas fazia parte dos valores dominantes que delimitaram o campo das atribuições institucionais e o mundo da política convencional" (Bonelli, 2002, p.161). Os promotores e procuradores de São Paulo tiveram, para Bonelli, um peso significativo na definição institucional de perfil mais autônomo e insulado do MP no Brasil.

O embate entre "profissionalismo e política", todavia, continuou presente no MP, segundo a autora,

"Mesmo depois das mudanças constitucionais sobre as atribuições do Ministério Público, que garantiram sua autonomia e independência e reforçaram o ethos profissional, o conteúdo desta ideologia segue sendo objeto de disputas internas, particularmente quanto às relações com o Estado e a sociedade e com o papel do promotor de agente político, na defesa da cidadania e do estado democrático de direito" (Bonelli, 2002, p.167).

É justamente desta relação dos promotores e procuradores com o Estado e a sociedade que Arantes trata. Para ele, o voluntarismo político perpassa todo o MP e se caracteriza como a marca do órgão, com implicações exteriores a ele - e controversas, no mínimo, à ordem democrática. Conforme dados da pesquisa O Ministério Público e a Justiça no
Brasil por ele apresentados, 84\% dos membros do MP entrevistados concordavam com a afirmação de que "a sociedade brasileira é hipossuficiente, isto é, incapaz de defender autonomamente os seus interesses e direitos, e que, por isso, as instituições da Justiça devem atuar afirmativamente para protege-la" (Arantes, 2002, p.128). Assim, a atuação política do MP passa, sobretudo, pelo papel que seus membros atribuíram a si mesmos, o de principais agentes de defesa de direitos difusos e coletivos - o que não exige uma atuação direta na política por meio de cargos no Executivo ou no Legislativo, foco do trabalho de Bonelli. A "profissionalização" não distanciou os promotores e procuradores da política, mas foi reforçada por meio da ampla autonomia conquistada através dos processos endógenos tão bem interpretados por Rogério Arantes.

O segundo elemento que nos interessa, também relacionado à autonomia dos promotores e procuradores, é a combinação de discricionariedade com ausência de mecanismos de accountability, conforme salientado por Kerche (2007). A autonomia em si não seria um problema caso acompanhada de mecanismos institucionais de controle dessa burocracia, o que não se verifica no caso do Ministério Público brasileiro.

O órgão detém completa autonomia sobre a escolha da maior parte de seus quadros e sobre a organização de seus procedimentos internos, bem como estabelece sua própria agenda de atuação, planejando de forma relativamente independente como se dá sua presença geográfica pelo país, expansão e acesso pelo público. Tal como o Judiciário, - Ministério Público tem autonomia administrativa e financeira garantidas pela Constituição de 1988, de modo que elabora sua própria proposta orçamentária, cria e extin- 
gue cargos e serviços auxiliares, bem como estabelece a política remuneratória de seus membros e seus planos de carreira. Embora não possamos falar numa relação entre principal-agent de completa abdicação de poder de controle dos órgãos políticos sobre - Ministério Público, pode-se afirmar que há, no caso brasileiro, uma quasi-abdicação, nos termos de Kerche (2007). Isso porque,

“(...) houve, senão uma abdicação completa (porque os políticos ainda podem emendar a Constituição, modificar a legislação infraconstitucional ou interferir no orçamento proposto pelo Ministério Público), pelo menos uma delegação que garantiu boa margem de autonomia e uma amplitude de tarefas pouco comuns a órgãos estatais com integrantes não-eleitos. Em outras palavras, houve uma quasi-abdicação" (Kerche, 2007, p.270).

A ausência de um controle político mais efetivo sobre o MP também não foi resolvida pela criação do Conselho Nacional do Ministério Público (CNMP) em 2005, porque este é composto por uma maioria de membros do próprio órgão, não representando um "controle externo". A ausência de mecanismos de controle político e administrativo externo reforça a atuação dos membros do MP como agentes políticos da lei, nos termos de Arantes (2002).

Somada às garantias de autonomia conferidas ao órgão como um todo, a própria Constituição assegurou como princípio institucional do MP a independência funcional de seus membros, cujo conteúdo e limites não foram explicitamente organizados quer pela Constituição quer por legislação infraconstitucional ou interna ao órgão. Esta independência funcional passa a ser aplicada a um amplo rol de atribuições e mecanismos de atuação do órgão, que apenas cresceu desde 1988 e que compreende não só sua tradicional atuação privativa na ação penal pública, como a possibilidade de mobilizar procedimentos judiciais e administrativos (como a ação civil pública, inquéritos civis, notificações, requerimento de diligências, etc.) que acabam por envolver toda e qualquer área do Direito que o órgão deseje atuar em nome do "interesse público".

Percebe-se que a literatura avançou em compreender como a atuação do MP e de seus atores se dá em contextos e com resultados específicos. Especialmente, destacamos dois aspectos centrais: ampla gama de assuntos sobre os quais os membros de MP podem atuar em nome do "interesse público" e ausência de mecanismos de controle sobre esta atuação. A literatura, contudo, tem se concentrado em analisar esta ausência de controle e accountability do Ministério Público a partir de sua dimensão institucional, dando menos atenção à independência funcional de promotores e procuradores como fundamento que Ihes permite atuar como "gatekeepers" dos próprios serviços de justiça à população. Falta, assim, a compreensão de um elemento bastante relevante para a análise de políticas públicas: em que medida as escolhas realizadas pelos promotores acerca de quais casos devem (e como devem) ser levados adiante pelo MP, acabam abrindo ou fechando portas do Estado para determinados tipos de causas e de cidadãos.

\section{DISCRICIONARIEDADE DA BUROCRACIA DO MINISTÉRIO PÚBLICO}

A questão da discricionariedade da burocracia em sentido amplo tem sido estudada no campo das políticas públicas há várias dé- 
cadas. Inicialmente, os estudos focaram na discricionariedade e papel político dos burocratas de alto escalão, também chamados de burocracia sênior, e sua influência sobre os políticos e processos decisórios. Nos anos 80 a agenda passa a incorporar análise de outros atores, os burocratas implementadores, que estão longe das decisões políticas, mas que, como mostra a literatura, exercem amplo poder decisório, se tornando policymakers. Esta agenda ganha destaque em 1980, com o livro seminal de Michael Lipsky, Street-level Bureaucracy. Desde então, diversas pesquisas buscaram entender o poder decisório e discricionário das burocracias da ponta, compreendendo como suas interpretações e decisões afetam os resultados das políticas.

Para esta literatura, o estudo da discricionariedade é central para entender implementação, na medida em que é a partir do uso da discricionariedade que os burocratas tomam decisões que materializam as políticas, constroem a imagem do Estado perante os usuários, geram serviços ou sanções concretos e promovem acesso ou exclusão dos usuários. A discricionariedade é conceituada como o espaço de liberdade para tomada de decisão, nos limites do constrangimento imposto pelas regras. "Um agente público possui discricionaridade sempre que os efetivos limites de seu poder o deixam livre para fazer uma escolha entre possíveis cursos de ação e a inação" (Davis, 1971, p.4, tradução nossa).

Moller (2016) define a discricionariedade como o espaço de racionalidade usado para transformar uma regra geral em uma determinação específica (Moller, 2016). O uso da discricionariedade traz dilemas aos burocratas, que são pressionados ao mesmo tempo por conflitos das políticas, padrões profissionais, objetivos organizacionais, gestão e requisitos dos públicos alvo com quem interagem (Hupe \& Hill, 2007; Lipsky, 2010; Maynard-Moddy \& Musheno, 2003; Winter \& Nielsen, 2008, apud Moller, 2016).

A origem da discricionariedade remete a aspectos legais, gerenciais e contingenciais que permeiam as políticas públicas e, portanto, ela é praticamente inevitável. Questões como metas ambíguas, objetivos e valores em conflito, recursos escassos, categorias confusas, incertezas, evidências fracas, imprevisibilidade e assimetria de informação são apenas alguns dos fatores que levam ao maior ou menor espaço para discricionariedade dos agentes (Zacka, 2017).

Além disso, a literatura já apontou diversos elementos que influenciam o uso da discricionariedade: fatores relacionados ao background dos burocratas, como gênero, experiência, tecnicidade, educação, demografia e formação profissional (Moller, 2016; Evans, 2011; Ellis, 2011); fatores organizacionais e gerenciais, como os sistemas complexos nos quais operam diferentes tipos de valores e incentivos (May \& Winter, 2009; Ricucci, 2005; Lipsky, 2010, Hupe \& Hill, 2007); fatores relacionados a "características do público alvo", compreendidas de forma específica pelos burocratas (Moller, 2016); dimensões culturais e sociais (Maynard-Moddy \& Musheno, 2003; Stone, 2002; Riley \& Brophy-Baermann, 2005; Harrits \& Moller, 2013). Por fim, parte da literatura tem se dedicado a compreender como a dimensão das categorias profissionais e das relações com os pares influencia o exercício da discricionariedade. Neste sentido, o compartilhamento de backgrounds profissionais ou a relação cotidiana com os pares teriam influência sobre os valores profissionais do trabalho e, consequentemente, sobre as 
decisões tomadas pelos burocratas (Evans, 2011; Ellis, 2011).

O estudo da ação discricionária da burocracia tem tido bastante relevante para os autores preocupados com desenho e implementação das políticas. Zacka (2017) aponta que a teoria política tem se apropriado muito pouco dessas discussões, embora ela tenha uma ressonância direta com discussões sobre democracia e legitimidade, que têm sido pouco exploradas pela literatura em geral. O autor aponta que os burocratas lidam com regras e guias normativos que direcionam suas interpretações, mas estas podem variar enormemente dependendo do contexto e da cultura que encontram na realidade. Assim, cabe aos burocratas encontrarem formas criativas de adaptar e refinar as categorias administrativas para encaixá-las em realidades complexas. Cabe, portanto, a eles materializar questões que são teóricas "na letra da lei", mas concretas a partir de suas intervenções. Concepções genéricas como eficiência, justiça, responsividade, entre outras, só se tornam concretas a partir da ação discricionária de um burocrata.

Embora na literatura nacional já haja algum avanço no estudo da discricionariedade da burocracia do nível da rua em políticas sociais (Lotta, 2015) e em políticas do trabalho (Pires, 2011), há poucos avanços em relação à existência de uma atuação da burocrática do sistema de justiça, tema que tem sido objeto de estudo especialmente na literatura norte-americana. No Brasil, ganha contornos ainda mais específicos com a existência de uma organização como o Ministério Público, que desde a Constituição de 1988 tem como função fiscalizar e proteger os vários tipos de direitos coletivos - meio ambiente, patrimônio histórico e cultural, direito do consumidor e direitos sociais diversos
(Arantes, 1999). Ao exercer sua função, o MP, por um lado, amplia o acesso à justiça e, por outro, escolhe quais são os interesses a serem protegidos e como eles deverão ser protegidos.

Importante destacar a possibilidade que os membros do Ministério Público têm de não levar adiante casos que a eles chegam: a o poder discricionário de "não iniciar, não investigar, não processar, não entrar em acordo" (West, 1995, p.25, apud Kerche, 2007). Esse aspecto, também salientado por Kerche (2007), reforça o peso da discricionariedade dos promotores e procuradores no uso do inquérito civil e da ação civil pública. Sobre este aspecto - possibilidade de levar ou não adiante um caso, já há muito tempo Langbein (1974) alertou:

"A discricionariedade do promotor (...) significa o poder que possui de se recusar a processar em casos de responsabilidade criminal comprovável. É o poder do promotor de selecionar entre casos, entre casos de fato semelhantes, aqueles que deve perseguir e os que não deve. O agente público responsável pela aplicação da lei poderá escolher quais leis ele irá aplicar e contra quem" (Langbein, 1974, p.440, tradução e grifos nossos).

Especificamente acerca do Ministério Público, têm crescido nos últimos anos os estudos mais abrangentes sobre os promotores e procuradores que nele atuam. Coslovsky (2011) aponta que os estudos dos procuradores do MP se dividem em basicamente dois tipos:

"enquanto alguns trabalhos analisam os desafios decorrentes da excessiva discricionariedade dos procuradores e limitado controle e responsabilização (Arantes 2002; Sadek \& Cavalcanti 2003; Hochs- 
tetler \& Keck 2007; Kerche, 2007; Nóbrega 2007; Taylor \& Buranelli 2007), outros partem da ideia de que a discricionariedade é dada e buscam compreender as habilidades dos procuradores para fazerem as leis serem aplicadas (McAllister, 2008) e evitarem que as leis retrocedam (Mueller, 2006)" (Coslovsky, 2011).

Há ainda trabalhos que tentam compreender as práticas cotidianas desempenhadas pelos procuradores. Coslovsky (2011), por exemplo, analisa como os procuradores do MP passaram da condição de agentes subordinados para a de agentes públicos independentes e relevantes, ou seja, como se deu a construção de sua autonomia. Para isso, os promotores combinam estratégias para atuar em momentos de reforma, aproveitando as turbulências políticas como oportunidades.

Analisando a atuação cotidiana de promotores do estado de São Paulo, Silva (2001) argumenta que podem ser encontrados dois "tipos ideais" de promotores: promotores de gabinete e promotores de fato. Promotores de gabinete acreditam que sua responsabilidade é a de dar conta dos processos legais ligados à sua área. Eles tentam responder às demandas que surgem com o máximo de neutralidade e independência externa com relação às suas decisões. Esse tipo de promotor, portanto, "não usa os procedimentos extrajudiciais como meios de negociação, articulação e mobilização de organismos governamentais e não-governamentais" (Silva, 2001, p.134). Já os promotores de fato dão bastante relevância ao uso de procedimentos extrajudiciais. Eles se enxergam como "resolutores de problemas" e, em vez de processarem casos com distância, estabelecem relações próximas com organizações não governamentais, movimentos sociais, burocracia pública ou outros atores relevantes na resolução dos problemas.

Coslovsky (2011) parte dos achados de Silva (2001) e busca dar um passo além, examinando como grupos de procuradores, representados pelos dois tipos ideais encontrados por Silva (2001), coexistem sob a mesma organização e, ainda, estabelecem processos, estruturas e políticas organizacionais independentes e sobrepostas. Estes grupos cooperam entre si, mas também competem por recursos e se autocontrolam.

Coslovsky também aponta que embora a atuação do MP encoraje um processo de rotinização, alguns grupos "atuam identificando casos importantes, recrutando aliados externos e gerando inovações para solução de problemas". Essa atuação não resulta apenas de decisões individuais, mas é produzida por estes grupos que "operam dentro e constroem para fora do próprio MP" (Coslovsky, 2011, p.70).

Enfim, o que se percebe das poucas pesquisas existentes sobre burocracia do MP é que apesar de já oferecerem pistas sobre como promotores e procuradores exercem seu poder discricionário, estes trabalhos têm pouco a dizer acerca da interação direta destes atores com o público em geral. Compreender melhor a atuação discricionária dessa burocracia e seu impacto no acesso dos cidadãos ao sistema de justiça é, assim, uma lacuna a ser ainda superada.

\section{AMPLIAÇÃO DA ATUAÇÃO, MANUTENÇÃO DA AUTONOMIA SEM ACCOUNTABILITY}

A carga de trabalho dos promotores em São Paulo é assustadora. De acordo com Coslovsky (2011), "assumindo que 1.400 promotores trabalham 200 dias por ano e dedicam 
4 dias por semana ao processamento de casos, em 2005 cada promotor processou 39 casos, participou de 4 audiências e julgamentos e escreveu 4 resumos e moções por dia" (Coslovsky, 2011, p.76). Em função dessa descomunal carga de trabalho, um dos principais mecanismos de enfrentamento adotado pelos promotores é a padronização de procedimentos. De acordo com o autor, a organização fornece aos seus promotores um roteiro com vários modelos de argumentos a serem utilizados nos processos e procedimentos administrativos, de forma a facilitar o trabalho; tais modelos "indicam quais violações valem a pena processar e como" (Coslovsky, 2011, p.76), o que desincentiva a inovação e o pioneirismo.

Por outro lado, promotores podem também ser bastante criativos no enfrentamento das questões que lhes chegam, e isso é possibilitado pela ampla autonomia funcional que promotores e procuradores conseguiram assegurar após 1988, conforme discutido anteriormente. De fato, a autonomia funcional decorre de garantias institucionais conquistadas na Constituição, mas não apenas. Os promotores podem ser categorizados como "burocratas do nível de rua", nos termos de Lipsky (1980), e porque a interação com a população/cliente é mediada por normas organizacionais, mas com ampla discricionariedade, o promotor possui liberdade para inovar. Comparando-os com os burocratas estudados por Lipsky, Coslovsky (2007) afirma:

“(...) promotores a) interagem diretamente com cidadãos; b) têm poder discricionário significativo; c) são sufocados por uma demanda por serviços muito superior ao que podem oferecer; d) esforçam-se para atingir objetivos que são ambíguos e conflitantes; e e) lidam com clientes involuntários, isto é, que preferiam não estar lá" (Coslovsky, 2007, p.9).

Assim, os "promotores em ação" podem se utilizar dos modelos padronizados fornecidos pela instituição, mas podem também encontrar soluções inovadoras para os casos com os quais lidam diariamente. E o que os permite assim atuar é a ampla autonomia funcional, com baixa accountability (Kerche, 2007).

A padronização de procedimentos decorre, conforme dito, da pesada carga de trabalho enfrentada por esta burocracia. Se, por um lado, a carga de trabalho é excessiva, por outro o Ministério Público buscou ampliar significativamente sua atuação a partir de 1988, conforme apontou Arantes (2002): defesa dos interesses metaindividuais (patrimônio público, consumidor, meio ambiente, idosos, crianças etc.), exclusividade na promoção da ação penal pública, controle externo das polícias. E esta ampla atuação vem sendo reforçada cotidianamente pela instituição.

Para explorar o tema da autonomia e como este é tratado institucionalmente no MP, buscamos no site do CNMP pela palavra "autonomia" no link para "Atos e Normas" do Conselho Nacional. A busca retornou 121 atos e normas, os quais foram analisados um a um. Desses, muitos são relacionados a procedimentos institucionais corriqueiros, como atribuições das unidades internas do MP, duração do mandato do Ouvidor nacional, regime de plantão do Ministério Público da União (MPU) e dos Ministérios Públicos Estaduais (MPE) etc. Outros, no entanto, tratam de procedimentos que visam à padronização institucional do MP e, em certa medida dela decorrente, à ampliação da sua atuação em áreas específicas (sobretu- 
do sociais). É o caso das áreas de educação infantil, saúde, igualdade étnico-racial, dentre outras, conforme listado no quadro abaixo.

\section{Quadro 1: Recomendações CNMP - padronização institucional e de procedimentos}

\begin{tabular}{|c|c|}
\hline Recomendação n 26/2015 & $\begin{array}{l}\text { Dispõe sobre a uniformização da atuação do Ministério Pú- } \\
\text { blico no processo de elaboração e implementação dos Sis- } \\
\text { temas Estaduais e Municipais de Atendimento Socioedu- } \\
\text { cativo, conforme disposto nas Leis Federais nos } 8.069 / 1990 \\
\text { e } 12.594 / 2012 \text {. }\end{array}$ \\
\hline Recomendação n’ 30/2016 & $\begin{array}{l}\text { Dispõe sobre a atuação do Ministério Público na garantia à } \\
\text { Educação Infantil. }\end{array}$ \\
\hline Recomendação n 33/2016 & $\begin{array}{l}\text { Dispõe sobre diretrizes para a implantação e estruturação } \\
\text { das Promotorias de Justiça da Infância e Juventude no âm- } \\
\text { bito do Ministério Público dos Estados e do Distrito Federal } \\
\text { e Territórios. }\end{array}$ \\
\hline Recomendação n 40/2016 & $\begin{array}{l}\text { Recomenda a criação de órgãos especializados na promo- } \\
\text { ção da igualdade étnico-racial, a inclusão do tema em edi- } \\
\text { tais de concursos e o incentivo à formação inicial e continu- } \\
\text { ada sobre o assunto. }\end{array}$ \\
\hline Recomendação n 41/2016 & $\begin{array}{l}\text { Define parâmetros para a atuação dos membros do Minis- } \\
\text { tério Público brasileiro para a correta implementação da } \\
\text { política de cotas étnico-raciais em vestibulares e concursos } \\
\text { públicos. }\end{array}$ \\
\hline Recomendação n 42/2016 & $\begin{array}{l}\text { Recomenda a criação de estruturas especializadas no Mi- } \\
\text { nistério Público para a otimização do enfrentamento à cor- } \\
\text { rupção, com atribuição cível e criminal. }\end{array}$ \\
\hline Recomendação n 44/2016 & $\begin{array}{l}\text { Dispõe sobre a atuação do Ministério Público no controle } \\
\text { do dever de gasto mínimo em educação. }\end{array}$ \\
\hline Recomendação n 48/2016 & $\begin{array}{l}\text { Sugere parâmetros para a atuação do Ministério Público } \\
\text { no controle do dever de gasto mínimo em saúde. }\end{array}$ \\
\hline
\end{tabular}

Fonte: elaboração própria a partir de consulta no site do CNMP - http://www.cnmp.mp.br/portal/atos-e-normas-resultados.

A especialização tem por efeito indireto a ampliação da atuação do MP, sobretudo em áreas sociais específicas. Alguns estudos vêm buscando demonstrar como a especialização do MP na área de educação infantil, por exemplo, gera um aumento da judicialização dessa política, por meio de pedidos de vagas em creches (Ximenes et al., 2019).
Importante salientar que, conforme apontam Lemgruber e colaboradores, a quantidade de promotorias temáticas não está relacionada à disponibilidade de promotores em cada UF: estados com baixos índices de membros do MP por 100 mil habitantes apresentam grande quantidade de promotorias temáticas, como é o caso de São Paulo 
e Rio de Janeiro; outros, com disponibilidade relativa bem mais alta de procuradores e promotores (como Amapá, Rondônia e Tocantins), informam um número bem mais baixo de núcleos especializados ou áreas de atuação (Lemgruber et al., 2016, p.25).

Se, por um lado, o MP vem buscando ampliar sua atuação nas diversas áreas de políticas sociais, por outro vem, através da atuação do CNMP, buscando resguardar sua autonomia e suas funções, contrapondo-se à atuação de outros Poderes. Isso pode ser exemplificado por meio de três notas técnicas abaixo brevemente descritas.

Em nota técnica de abril/2010 o CNMP se posicionou contrário a uma proposta de alteração da Lei 4.717/65 (lei da ação popular), na Lei 7.347/85 (lei da ação civil pública) e na Lei 8.429/93 (lei da improbidade administrativa) propostas pelo Deputado Paulo Maluf. As referidas alterações buscavam controlar a atuação dos membros do Ministério Público na defesa de probidade administrativa e legalidade. Na nota técnica, o CNMP traz para si a função constitucional de controlar seus próprios membros. Argumenta que cabe ao próprio CNMP a atividade fiscalizatória das atividades funcionais de seus membros - atividade esta que já seria realizada rotineiramente pelo conselho. Assim, a crítica apresentada pelo CNMP na nota técnica era a de que a alteração legislativa proposta iria ferir "a autonomia do Ministério Público, criando situação claramente intimidatória à atuação de seus membros na defesa da probidade administrativa, da legalidade e, consequentemente, da sociedade brasileira, implicam em disciplinar como se regras fossem, os excessos e abusos praticados por uma minoria de membros que, como exceções que são, vêm sendo tratados rigorosamente pela atividade fiscalizatória exercida por este Conselho Nacional do Ministério Público".

A Nota Técnica No 7, de 26 de janeiro de 2016 teve como objetivo se contrapor às Resoluções 1 e 2/2010 do Conselho Superior de Polícia e à Resolução Conjunta no. 1/2015 do Conselho Nacional dos Chefes de Polícia Civil visando resguardar o papel e a autonomia do Ministério Público. As referidas resoluções foram propostas por órgãos da polícia buscando restringir o exercício do controle externo realizado pelo MP às atividades policiais, por meio de regulamentação de sua atuação.

Contrário às resoluções da polícia, o CNMP redigiu a Nota Técnica afirmando, em primeiro lugar, a ilegalidade na edição de normas, por parte da polícia, que afete órgãos externos a ela. Ou seja, a própria edição das normas já seria ilegal. Ao mesmo tempo, ao criticar o conteúdo das normas, o CNMP reforça a autonomia funcional e administrativa do MP e suas atribuições funcionais de "zelar para que os Poderes Públicos e os serviços de relevância pública sejam efetivamente bem prestados" (p. 4). Reforça também a ideia de que o controle externo da atividade policial seria instrumento de freios e contrapesos do Estado brasileiro, inserindo-se no papel constitucional do Ministério Público de garantia dos direitos.

Processo semelhante de resguardo das atribuições e autonomia do MP pode ser visualizado no exame da Nota Técnica no 12, de 23 de maio de 2017. Esta nota foi elaborada como um subsídio às discussões sobre o Projeto de Lei 233/2015 que tramitava no Senado Federal buscando estabelecer regramento para o inquérito civil e procedimentos correlatos destinados à defesa do patrimônio público e social, do meio am- 
biente e de outros interesses difusos e coletivos.

Na referida nota, o CNMP inicia reforçando a função e autonomia institucional do MP nestes assuntos e aponta que a legislação proposta possivelmente traria, como consequência, riscos à autonomia do Ministério Público e ao êxito das investigações.

Baseando-se no artigo 129, III, da Constituição da República, o CNMP reforça sua função de promover "inquérito civil e a ação civil pública, para a proteção do patrimônio público e social, do meio ambiente e de outros interesses difusos e coletivos", apontando que o "Ministério Público é a única autoridade constitucionalmente encarregada de conduzir o inquérito civil, circunstância que traz também, como consectário inafastável, a responsabilidade por conhecer e deliberar sobre as providências necessárias ao esclarecimento dos fatos apontados como ilícitos". A partir desse elemento institucional, a nota reforça a autonomia do MP em promover alteração legislativa de qualquer rotina relativa à sua atribuição - o que estaria sendo realizado de forma inconstitucional pelo Senado, segundo argumentam os conselheiros.

Esses exemplos ilustram a atuação do CNMP no sentido de reforçar a autonomia do MP - sem que isso implique, no entanto, aumento da accountability. Assim, a análise exploratória da atuação recente do CNMP sinaliza para a tendência de "autonomia sem accountability" (Kerche, 2007; Kerche et al., 2019), observada desde o início do processo de construção institucional do Ministério Público, que não apenas se manteve presente, como vem sendo reforçada por atos e normas do CNMP. Por outro lado, não há indícios, nos estudos mais recentes sobre o MP (Avritzer e Marona 2017; Kerche e Marona, 2018), de um movimento institucional no sentido de ampliar a accountability, fazendo com que a atuação de promotores e procuradores seja pouco transparente para além do que está descrito nos processos administrativos ou judiciais. A autonomia é ampla, o controle é baixo.

Também relacionada com a autonomia, outra questão que vem sendo apontada pela literatura (CNJ, 2018) é a preferência por procedimentos extrajudiciais, ao invés do uso das ações coletivas, por parte dos promotores e procuradores. O que muitos promotores relatam é que assim eles conseguem acompanhar e definir melhor o desfecho dos casos - reforçando, portanto, sua autonomia. Afirmam que os Termos de Ajustamento de Conduta (TACs) são muito mais eficientes do que as ações civis públicas (ACPs) para a resolução dos problemas a que se propõem, particularmente porque os procedimentos extrajudiciais - tais como - Inquérito Civil e o TAC - garantem maior controle sobre o caso, quando comparados aos instrumentos que ensejam a "judicialização", que transferem o controle para o Judiciário. Por isso, promotores e procuradores preferem não "judicializar a maioria dos casos", conforme aponta pesquisa sobre ações coletivas no Brasil (CNJ, 2018): em média apenas $20 \%$ das demandas viram ações civis públicas ou outras ações judiciais, as quais resolvem 30\% dos problemas a que se propõem, ao passo que os TACs resolvem cerca de $80 \%$ dos problemas.

Essa mesma tendência - preferência por procedimentos extrajudiciais - foi observada por Coslovsky (2008). Analisando a atuação de promotores na fiscalização de quatro tipos de empresas consideradas "problemáticas" no Brasil - carnicicultura, suinocul- 
tura, produção de carvão e mineração de granito - o autor demonstra que embora os "promotores padrão" sejam aqueles que "adotam a abordagem mais confortável, isto é, enfrentam o problema com trâmites burocráticos" (Coslovsky, 2008, p.10), outros se mostram "resolvedores de problemas" (Silbey, Housing, Coslovsky, 2007), isto é, "usam a lei, mas não se limitam por ela nem se limitam a ela" (Coslovsky, 2008, p.11). Estes últimos não apenas fiscalizam e punem, mas são criativos e inovadores na busca por soluções, e até "deixam passar pequenas irregularidades" para viabilizar os acordos e conduzir empresas irregulares a buscarem a conformidade à lei, atuando intensamente no diálogo entre as partes envolvidas.

Importante notar que a preferência por instrumentos extrajudiciais dá ao promotor maior discricionariedade na condução do caso, quando comparada com a opção (burocrática) pela ação judicial.

\section{CONSIDERAÇÕES FINAIS}

Iniciamos o presente artigo apontando a escassez existente na literatura da ciência política e das políticas públicas de estudos sobre a discricionariedade da burocracia pública das instituições que compõem o sistema de justiça e de como esta discricionariedade afeta sua atuação. Este é um problema relevante, embora pouco estudado, pois a atuação e discricionariedade dessa burocracia afeta - ou pode afetar - significativamente não apenas a garantia de direitos e as políticas públicas propriamente ditas, mas, antes disso, o próprio acesso à justiça.

O esforço aqui empreendido foi o de buscar suprir essa lacuna, por meio do diálogo entre os estudos sobre os atores do sistema de justiça - em especial do Ministério Público, por um lado, e a literatura sobre burocracia e discricionariedade, por outro. A discussão apresentada deixa claro que a autonomia dos promotores e procuradores é ampla e a mesma foi não apenas assegurada pela Constituição de 1988, conforme trabalhos anteriores já haviam demonstrado (Arantes, 2002; Kerche, 2007; Silva, 2001), mas vem sendo reforçada por uma atuação institucional que visa fortalecê-la, o que aparece nas manifestações do CNMP contrárias às tentativas legislativas restritivas. Ademais, neste mesmo sentido, a preferência pela atuação extrajudicial ao invés da judicial, a possibilitar soluções menos "burocráticas" aos casos enfrentados pelo MP, dando maior poder discricionário aos seus atores (CNJ, 2018), ilustra o argumento.

Enfim, lançamos luz sobre a questão da autonomia e discricionariedade dos promotores e procuradores do MP, fator essencial na seleção e condução de casos concretos. A inovação trazida decorre da junção de duas literaturas até então pouco integradas. $O$ próximo passo, desta e de futuras pesquisas, é compreender os processos pelos quais a autonomia funcional e a discricionariedade impactam as políticas públicas e o acesso à justiça no Brasil.

\section{REFERÊNCIAS}

Arantes, R. B. (2002). Ministério Público e Política no Brasil. 1. ed. São Paulo: Sumaré/Educ.

Avritzer, L.; Marona, M. (2017). A tensão entre soberania e instituições de controle na democracia brasileira. Dados, v.60, n. 2, pp. 359-393.

Bonelli, M. G. (2002). Profissionalismo e Política no Mundo do Direito. São Carlos: EdUFSCar, Editora Sumaré.

Carvalho, E.; Leitão, N. O novo desenho institucional do Ministério Público e o processo de judicialização da 
política. Revista Direito GV, v. 6, n. 2, p. 399-421, 2010. Coslovsky, S. (2008). Respeito às Normas e Crescimento Econômico: como promotores públicos garantem o cumprimento das leis e promovem o crescimento econômico no Brasil. IPEA, Texto para Discussão n 1355, Brasília.

(2011). Relational Regulation in the Brazilian Ministério Público: the organizational basis of regulatory responsiveness. Regulation \& Governance 5, 70-89.

Dubois, V. (1999). La vie au guichet. Relation administrative et traitement de la misère. Paris: Economica.

Freitas, H.; Oliveira, M.; Saccol, A.; Moscarola, J. (2000). O método de pesquisa survey. Revista de Administração, São Paulo, vol.35, n.3, p.105-112.

Hupe, P.; Hill, M. (2007). "Street-Level Bureaucracy and Public Accountability." Public Administration 85 (2):279-99 https://doi.org/10.1111/j.14679299.2007.00650.x.

Kerche, F.; Marona, M. (2018). O Ministério Público na Operação Lava Jato: como eles chegaram até aqui? In: KERCHE, Fábio, FERES Jr., João. (coords.) Operação Lava Jato e a democracia brasileira. São Paulo: Editora Contracorrente, pp. 69-100.

Kerche, F.; Oliveira, V. E.; Couto, C. G. (2019). "CNJ e CNMP: Instrumentos de Accountability?". Mimeo, Rio de Janeiro, São Paulo.

Kerche, F. (2007). "Autonomia e discricionariedade do Ministério Público no Brasil". Dados, 50(2), 259-279.

Lemgruber, J.; Ribeiro, L.; Musumeci, L.; Duarte, T. (2016). Ministério Público: Guardião da Democracia Brasileira? Centro de Estudos de Segurança e Cidadania (Cesec), Rio de Janeiro.

Lipsky, M. (2010). Street-level bureaucracy: dilemmas of the individual in public service. New York: Russell Sage Foundation.

Lotta, G. S. (2015). Burocracia e Implementação de Políticas de Saúde. Ed. Fiocruz, Rio de Janeiro.

Maynard-moody, S.; Musheno, M. (2001). Social equities and inequities in practice. Public Administration Review, v. 71, n. S1, p. S16-S23.

. (2003). Cops, Teachers, Counselors: Narratives of Street-Level Judgment. Ann Arbor: University of Michigan Press.

Mendes, C. H.; Oliveira, V. E.; Arantes, R. B. (Coord.). (2018). Ações Coletivas no Brasil: temas, atores e desafios da tutela coletiva. Relatório Analítico Propositivo, Conselho Nacional de Justiça. In: http:// www.cnj.jus.br/files/conteudo/arquivo/2018/03/799b01d7a3f27f85b334448b8554c914.pdf. Acessado em
26/07/2018.

Møller, M. (2016). "She isn't someone I associate with Pension" - A vignette study of professional reasoning. Professions \& Professionalism, v. 6, n. 1.

Møller, M.; Østergaard, D. S. (2013). "Disciplining Disability under Danish Active Labour Market Policy." Social Policy and Administration 47 (5):586-604.

Pires, R. (2011). Beyond the Fear of Discretion: Flexibility, Performance, and Accountability in the Management of Regulatory Bureaucracies. Regulation \& Governance, v. 5, n. 1.

Riccucci, N. M. (2005). Street-level bureaucrats and intrastate variation in the implementation of temporary assistance for needy family's policies. Journal of Public Administration Research and Theory, 15, 89-111. doi:10.1093/jopart/mui005

Riley, D. D.; Bryan E. Brophy-Baermann. (2006). Bureaucracy and the Policy Process. Lanham: Rowman and Littlefield.

Silva, C. A. (2001). "Promotores de Justiça e Novas Formas de Atuação em Defesa de Interesses Sociais e Coletivos". Revista Brasileira de Ciências Sociais, vol.16, $n^{\circ} 45$.

Ximenes, S. B.; Oliveira, V. E. de; Silva, M. P. (2019). "Judicialização da educação infantil: efeitos da interação entre o Sistema de Justiça e a Administração Pública". Revista Brasileira de Ciência Política [online], n.29, pp.155-188.

Data de submissão: 02/07/2019

Data de aceite: 22/01/2020 